\title{
WELDING OF NITINOL BY SELECTED TECHNOLOGIES
}

\author{
Tomáš Kramár, Jan TAuer, Petr Vondrouš*
}

\author{
CTU in Prague, Faculty of Mechanical Engineering, Department of Manufacturing Technology \\ * corresponding author: petr.vondrous@fs.cvut.cz
}

\begin{abstract}
Nitinol is a perspective alloy that is difficult to weld because of its high sensitivity to heat, atmospheric gases and the NiTi phase instability. We evaluated several welding techniques with regard to their applicability to weld fine pseudoelastic NiTi wires. Namely, we tested the microplasma arc, laser, electron beam, resistance and capacitor discharge welding. In conclusion, the behaviour of the weld for any of the implemented welding techniques is similar; it leads to a loss of mechanical properties in the welded joint caused by a recrystallization and an increased amount of brittle intermetallic phases. Yet, under perfect shielding and with a minimum heat input, the welds could, as a whole, retain the majority of their properties, and, as such, have the desired properties close to the base metal.
\end{abstract}

KEYWORDS: NiTi; welding; brittleness; pseudoelasticity; PAW; LBW; EBW; RBW; CDW.

\section{INTRODUCTION}

Nitinol is a nearly equiatomic alloy of $\mathrm{Ni}$ and $\mathrm{Ti}$ and is also called Niti or titanium nickelide. This material belongs to the group of shape memory alloys (SMA). It has very specific properties, such as shape memory, pseudoelasticity, biocompatibility, etc. The possibilities of the Nitinol use range from its application in biomedicine, Figure 1 aerospace, sensorics, actuators, etc. The material's mechanical properties are directly connected to the reversible phase transformation of martensite and austenite.

The joining of NiTi is often needed to form the final product. In this paper, we focus on the wire joining designated for the production of stents. The stents, unless laser cut from a tube, are produced by knitting a wire that needs to be connected. There are several joining methods feasible for the wire joining, i.e., crimping, welding, adhesive joining and brazing.

Adhesive joining and brazing can bring forward the problems with the product's certification, corrosion resistance and biocompatibility; this is due to the fact that another material is being used. In the present research paper, these methods are omitted.

Crimping and mechanical joining are often used for the NiTi wire joining. On the one hand, they are strong and crimping with the NiTi tube can be done. They are also used for the placement of Au X-ray markers. On the other hand, using crimping increases the product size, which is negative for a minimally invasive surgery. An example of crimping is shown in Figure 2

Another applicable technology and the focus of this research is the autogenous welding. Only the base material (BM) is used, thus the problems with product certification and corrosion are smaller. The weld size is close to that of the original wire, so there is no product size increase. While welding has many advantages while, it can also cause metallurgical changes, a change of the original properties - e.g., brittleness, a decrease

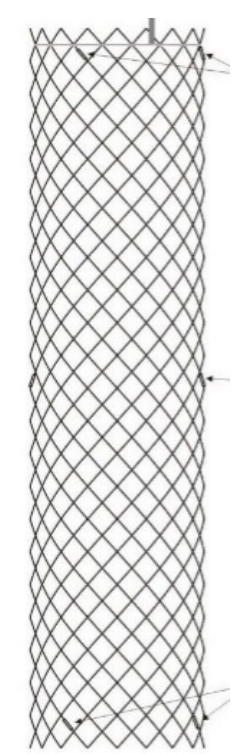

Figure 1. NiTi Stent [1].

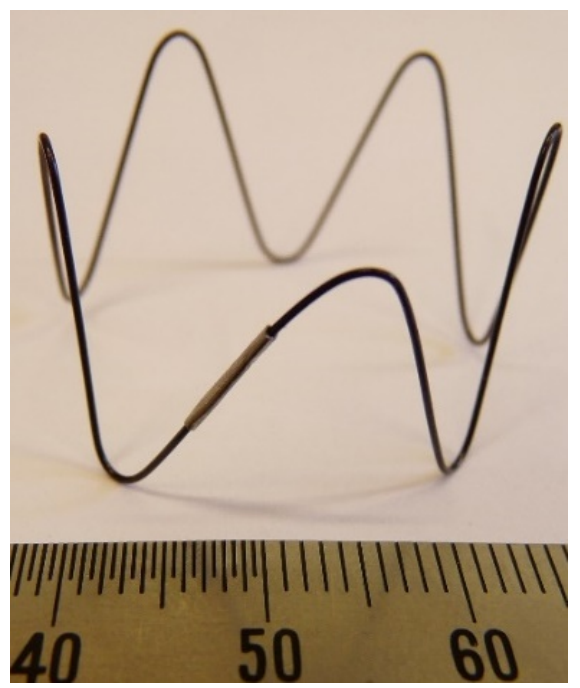

Figure 2. Crimped NiTi wire $(\varnothing 0.45 \mathrm{~mm}$, shape set, dark oxide). 


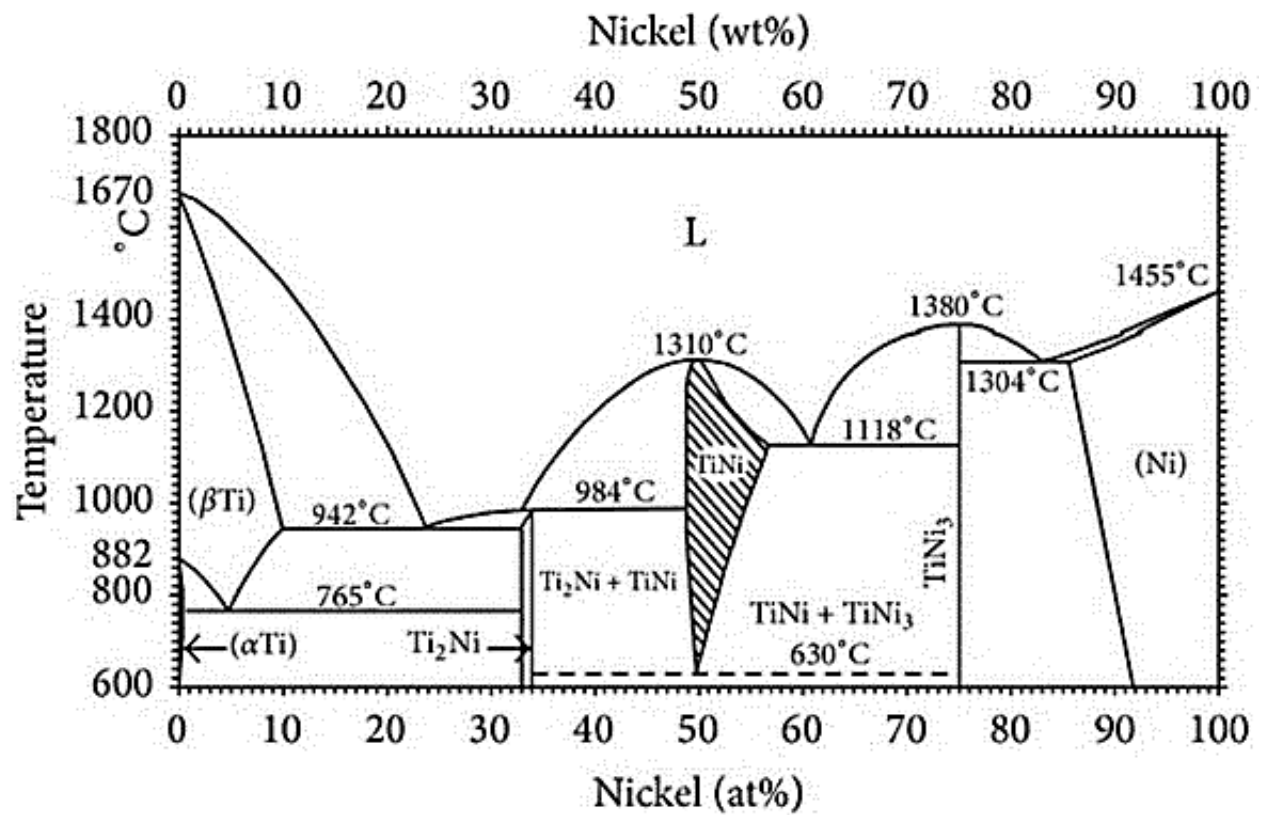

Figure 3. Binary diagram of Ni-Ti [2].

of strength, etc. A high quality weld is not easy to make. Nitinol is receiving a lot of attention from researchers and much about welding difficulties can be understood from literature; however, a comparison of several welding techniques by one welding laboratory has not been done yet.

The basics for understanding the welding process is the binary diagram, in Figure 3 . The desirable NiTi phase is shown hatched and it occupies only a very narrow zone; under $630^{\circ} \mathrm{C}$, it is just line at 50 at. $\% \mathrm{Ni}$, 50 at.\% Ti. Outside of this narrow central zone, the brittle phases $\mathrm{Ti}_{2} \mathrm{Ni}$, $\mathrm{TiNi}_{3}$ are formed, if there is an excess of $\mathrm{Ti}$ or $\mathrm{Ni}$ in the matrix. $\mathrm{Ti}_{2} \mathrm{Ni}, \mathrm{TiNi}_{3}$ are stable intermetallic phases that have undesirable properties compared to the base metal (BM). If the volume of these precipitates increases, the joint would be unacceptable. These intermetallic phases are promoted by the heat input and the impurities: mainly oxygen, nitrogen, iron contamination, etc. [2 6].

Based on reading, we may sum up the experience with NiTi welding as follows:

- grain coarsening in the heat affected zone (HAZ);

- severe grain coarsening in the weld metal (WM);

- after welding, an originally fully austenitic NiTi partially transforms into martensite;

- the precipitation of hard phases in WM, HAZ most often $\mathrm{Ti}_{2} \mathrm{Ni}$ and $\mathrm{Ni}_{3} \mathrm{Ti}, \mathrm{Ni}_{4} \mathrm{Ti}_{3}$.

Most of the NiTi semi-products in the medical industry are wires and tubes and they undergo a thermomechanical processing; e.g., the drawing and annealing have a great influence on the anisotropy, the grain size and, thus, both the phase transformations and the mechanical properties.

This article focuses on the evaluation of NiTi welding using several technologies in one laboratory, com- paring their results with the same equipment and methodology and on the base of that, stating the basic rule for welding, suggesting the best technology and finding the technology limits. In this research, the post-weld heat treatment (PWHT) is not considered.

\section{MATERIAL AND MEthods}

A homogeneous welding without a filler wire (i.e., autogenous) of NiTi wires using selected welding technologies was done.

\subsection{BASE Metal (BM)}

Fort Wayne Metals medical grade NiTi\#1 was used as the base metal; 51 at.\% Ni, 49 at.\% Ti. The declared properties of the wire are: sum of impurities $<0.1 \%$, inclusion area is $0.8 \%$, inclusions max. size $12.5 \mathrm{\mu m}$. The wire is fully austenitic at a room temperature. Several diameters $(0.15,0.2,0.38,0.46 \mathrm{~mm})$, heat treatment (as drawn, straight annealed) and surface finishes (etched, dark oxide) were used. The different wire diameters were selected to find the minimum diameter that could be processed by each of the welding technologies. All the different diameters are cold- worked, have a similar microstructure (small NiTi grains with drawing elongated precipitates) and similar mechanical properties (the tensile test results of BM are shown in Figures 12 and 14). The source of impurities may also come from the surface state of the wire; e.g., the oxide layer. Thus, several qualities of surface finishes were used.

The prerequisites of the welding methods selection were: a) an autogenous welding without a filler wire, b) the energy control must enable a pulse of $0.1-5 \mathrm{~J}$ (for wires of $\varnothing 0.15-0.46 \mathrm{~mm}$ ), c) the possibility to use the Ar gas for the shielding. At the "Laborator̆ výuky svářečských technologiî", Faculty of Mechanical 


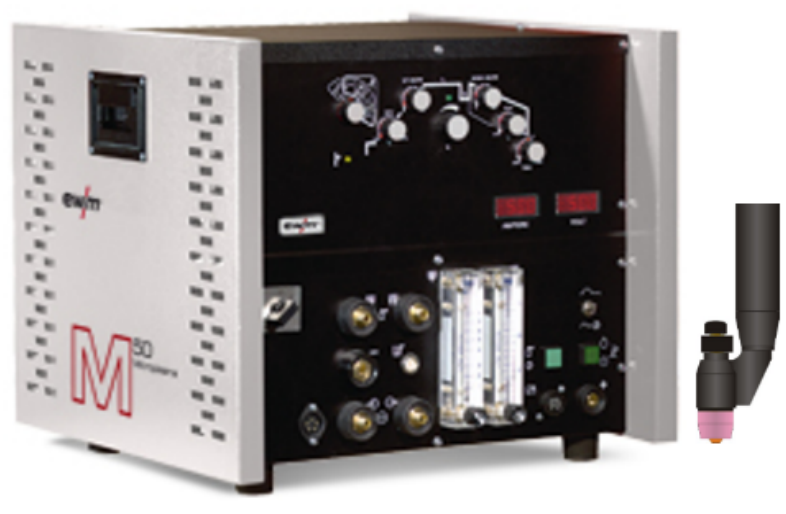

Figure 4. EWM Microplasma 50 [7].

Engineering of CTU in Prague and in a cooperation with several companies, we tried these technologies: the micro plasma arc, the laser, the electron beam, the resistance butt and the capacitor discharge welding.

The welds were tested for mechanical properties, tensile strength and hardness. An optical microscopy was done. The welds were tested in the welded state.

\subsection{Microplasma Arc Welding ( $\mu$ PAW)}

The microplasma welding was selected as the most precise of the arc welding techniques. The pilot arc and transferred arc current are stable and can be regulated between 2-50 A, with a precision of $0.1 \mathrm{~A}$. The source enables a pulse control from $0.06 \mathrm{~s}$. The welding source and the torch are in Figure 4 The EWM welding source enables the energy pulse to start from around $4 \mathrm{~J}$. The smallest energy pulse of the source $(4 \mathrm{~J})$ could not be used for small diameters (up to $0.2 \mathrm{~mm}$ ), because the energy would melt the wire exceedingly. The Ar 4.8 shielding gas was used as a plasma and shielding gas.

\subsection{Laser Beam Welding (LBW)}

The LBW is a precise fusion welding technique used widely in the industries, where power, pulse time, i.e., energy, can be varied so that it is suitable for different needs, the microjoining of electronics, or for shipbuilding. The welds were done in a cooperation with Novapax, s.r.o. on the fiber laser LRS EVO, in Figure 5. This laser is a hand manipulated laser used for a tool repair. It is equipped with magnifying optics suitable for work with wires from $0.1 \mathrm{~mm}$. The welding pulse energy can be controlled easily, starting from $1 \mathrm{~J}$ and a duration of $4 \mathrm{~ms}$. It is suitable for NiTi. The problem of laser welding is the variation of absorptivity, especially for small wires, so the surface state of the wire is important for the uniformity of results. The shielding was done in argon and the minimum laser spot size was $0.2 \mathrm{~mm}$, Gauss profile.

\subsection{Electron Beam Welding (EBW)}

The EBW has similar properties as the laser; furthermore, it operates in a vacuum, so oxidation is minimized. The EBW welder made by Cambridge

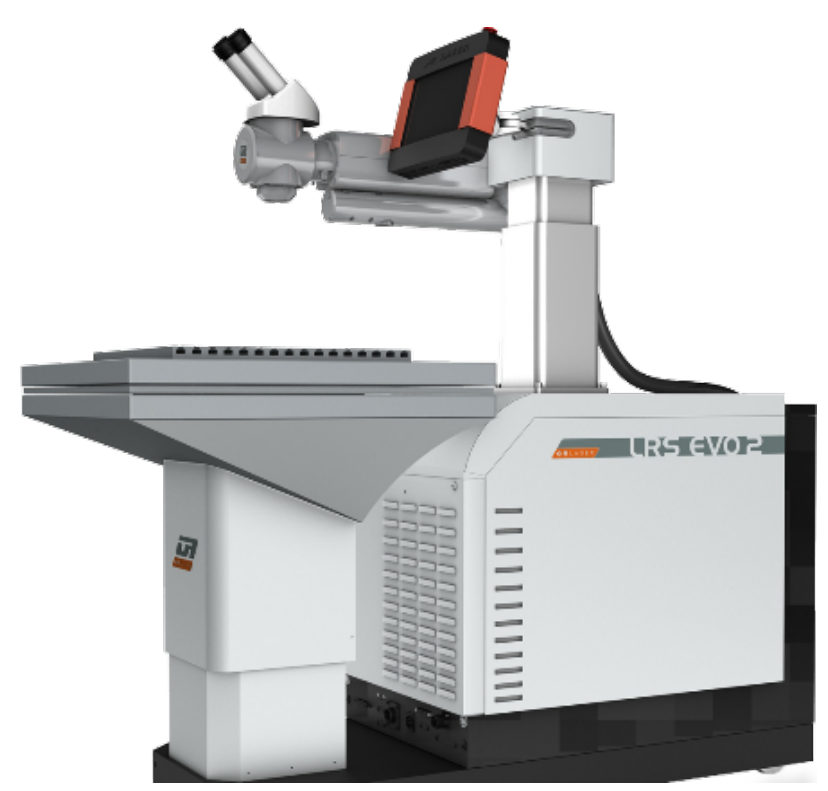

FiguRE 5. LRS EVO [8].

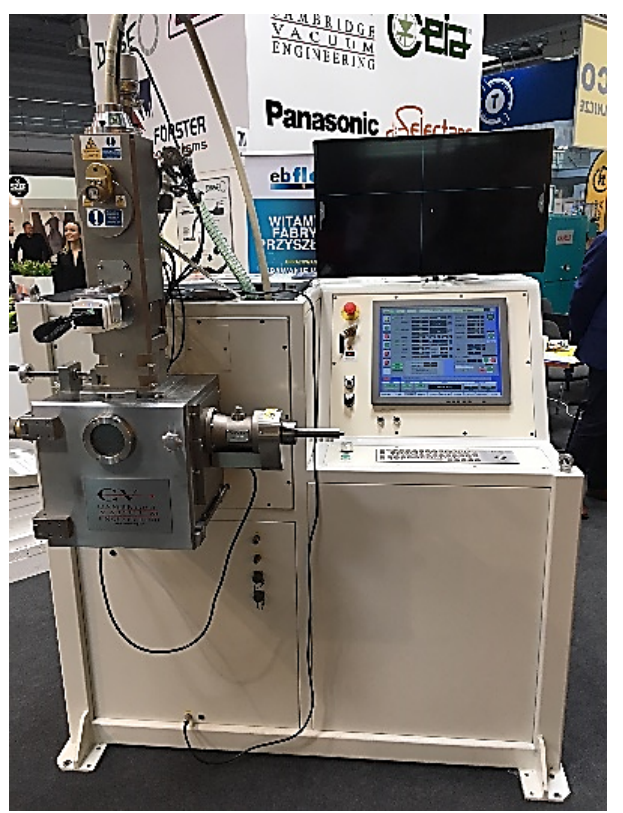

Figure 6. CVE - EBW welding source $60 \mathrm{kV}$.

Vacuum Engineering, Ltd., was used, as can be seen in Figure 6. It operates with $60 \mathrm{kV}$ and the minimum current is $0.1 \mathrm{~mA}$. The beam spot size was $50 \mu \mathrm{m}$. The source enables the precise welding of wires from $0.1 \mathrm{~mm}$ in diameter.

\subsection{Resistance Butt Welding (RBW)}

The RBW is a pressure welding technology used widely for wires, rods, where the Joule heat generated by the resistance is accompanied by an axial force. Due to the fast axial movement, the fully fused material leaves the joint creating a flash, which is subsequently removed away. Thus, the material in the WM is not fused. A machine from STRECKER, type 0F-LNVV20, using an Ar shielding, was employed. The source has a $0.3 \mathrm{kVA}$ transformer with stepless voltage from 


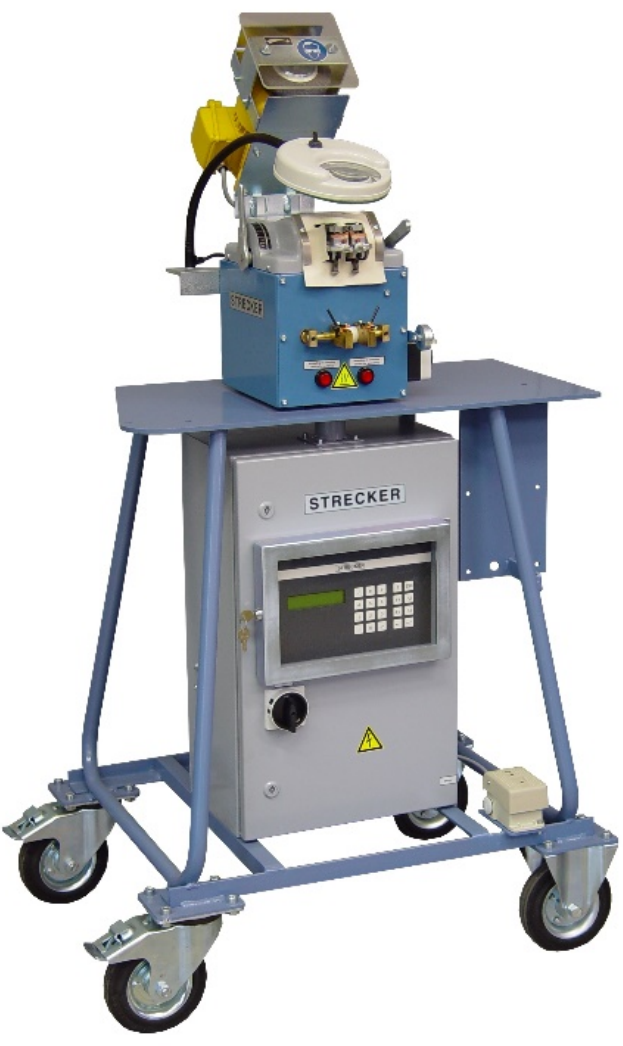

FiguRE 7. Strecker 0F-LNV-V20 [9].

0.12 up to $1.44 \mathrm{~V}$; the voltage was adjusted according to the wire diameter, see Figure 7. The machine is equipped with a magnifying lens and was applied on wires with a diameter of $>0.18 \mathrm{~mm}$.

\subsection{Capacitor Discharge Welding (CDW)}

The CDW is a pressure welding technology, where the Joule heat is generated by a capacitor discharge and the force is applied simultaneously. The pulse energy is regulated by charging the voltage of capacitors. The pulses are extremely short. A BT-2 machine made by Svarservis, under an Ar shielding, was used, Figure 8 . The voltage and current, as measured by an oscilloscope at the joint during the welding in the setting applied, can be seen in Figure 9. The pulse length is around $40 \mu \mathrm{s}$, the energy in one pulse is between $40-80 \mathrm{~mJ}$. This method enables the shortest pulse, but the energy cannot be precisely controlled and the source is not prepared for automation.

\section{Results And Discussion}

\subsection{Microplasma Arc Welding ( $\mu$ PAW)}

The smallest energy pulse enabled a welding of diameters $0.38,0.46 \mathrm{~mm}$. The used parameters for $0.38 \mathrm{~mm}$ dark oxide wire were: $5 \mathrm{~A}$, voltage approx. $15 \mathrm{~V}, 1$ pulse $0.06 \mathrm{~s}$ (4.5 J pulse, efficiency and losses to $\mathrm{Cu}$ nozzle were neglected). The welding was done in $\mathrm{Ar}$ 4.8, flow $5 \mathrm{l} / \mathrm{min}$.

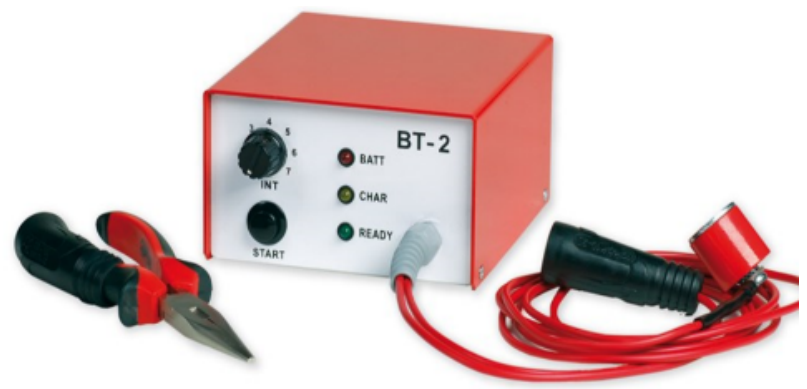

Figure 8. Capacitor discharge welding source BT$2[10$.

The first experiment involved a short evaluation of the presence and absence of the effects of the dark oxide layer on the tensile strength; respectively, its removal by a manual grinding before welding. It was found out that the presence of the dark oxide layer has a negative effect on the weld strength, causing a decrease and instability of the tensile test results. This fact was proved by the results of a bachelor's thesis by Jan Tauer [11, who found out that the oxide removal by grinding immediately before the welding improves the strength by up to $50 \%$. From this reason, all dark oxide samples were successively grinded before the welding.

In Figures 10 and 11, a comparison of the weld metal (WM) structure dependent on the Ar shielding can be seen. The influence of the atmospheric gases (oxygen) on the crystallization and hardness can be understood well once the Ar shielding during welding is interfered with by the normal atmosphere, e.g., by the turbulent flow of Ar from the shielding nozzle. Under the conditions of a perfect Ar shielding, the unwanted precipitates are limited to the grain boundary and the hardness stays low $(280 \mathrm{HV})$, close to BM hardness (250-350 HV). Under the conditions of an imperfect Ar shielding (atmospheric contamination), a large amount of precipitates is visible, and these precipitates show a dendritic growth. Also, hardness increases. The available literature states that the oxygen presence facilitates the $\mathrm{Ti}_{2} \mathrm{Ni}$ formation [3, 5, 6], which is also the first phase to crystallize, according to the binary diagram. The formation of $\mathrm{Ti}_{2} \mathrm{Ni}$ will also be accompanied by the $\mathrm{TiNi}_{3}$ precipitation, in order to establish an equilibrium.

The range of the tensile strength of the $\mu \mathrm{PAW}$ welds was $370-480 \mathrm{~N} / \mathrm{mm}^{2}$ under perfect shielding conditions. Some specimens displayed a pseudoelasticity during the tensile test, some fractured before reaching the transformation stress. The measured ultimate tensile strength (UTS) was roughly the value of the NiTi transformation stress (upper plateau stress, UPS). To conclude, this welding method is not suitable for highly demanding welds and a serious decrease of properties is caused by the welding because of a high heat input. 


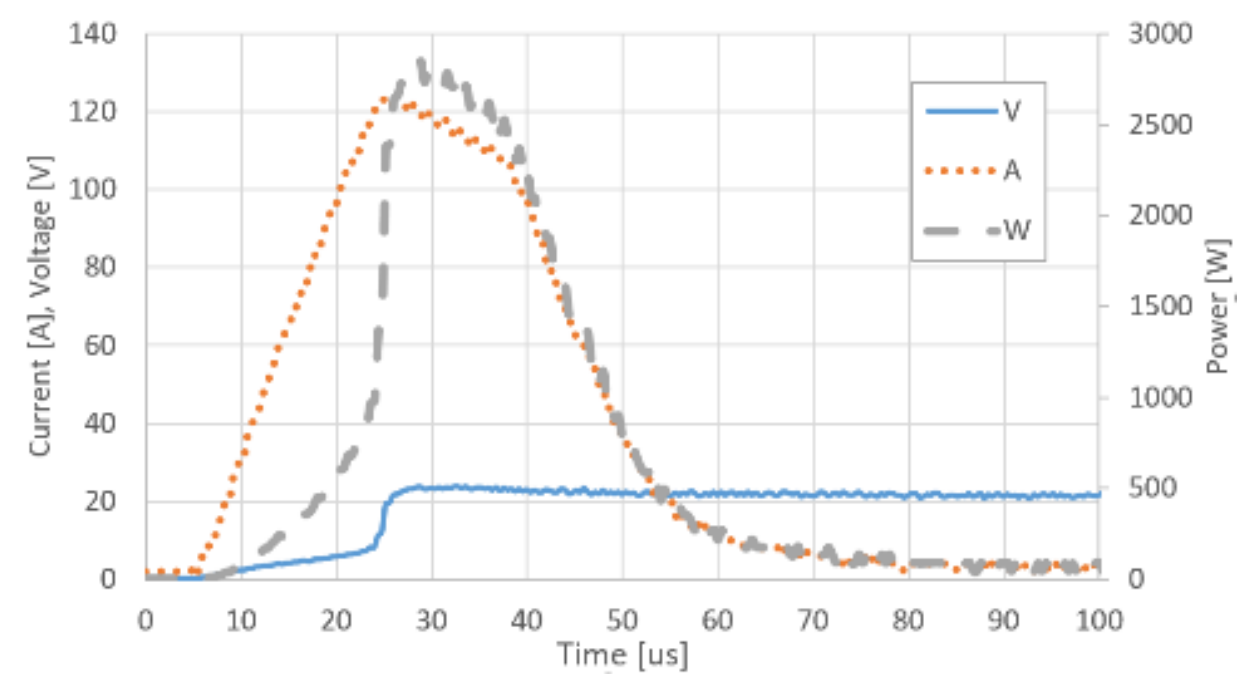

Figure 9. Capacitor pulse during the welding for used parameters $-U, I, P$ in time.

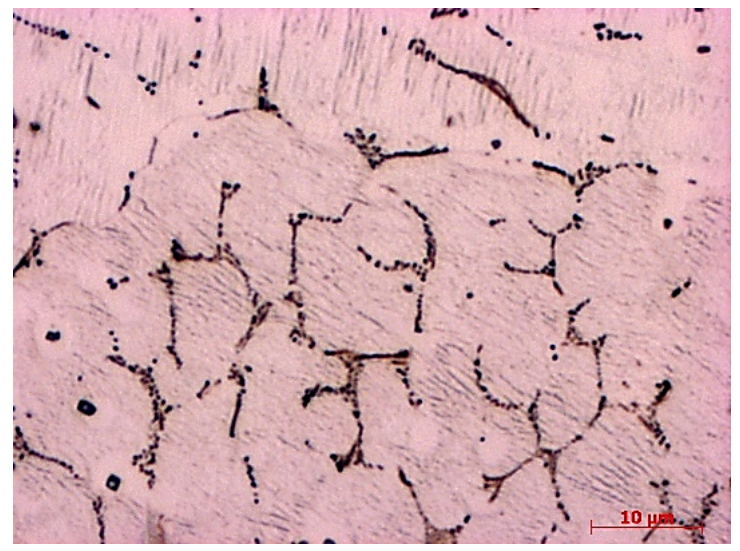

Figure 10. WM optical micrograph, $\mu \mathrm{PAW}, 5 \mathrm{~A}$, $0.06 \mathrm{~s}$, perfect Ar shielding, Kroll etchant, $280 \mathrm{HV}$, pink NiTi phase [12].

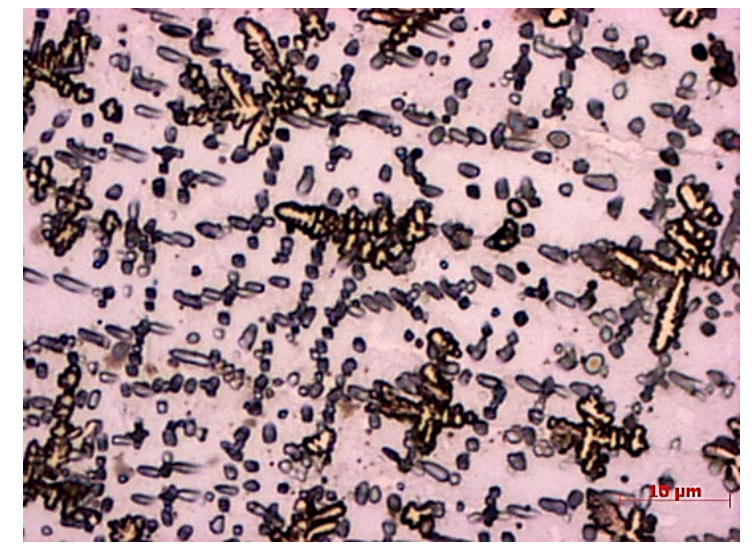

FiguRE 11. WM optical micrograph, imperfect Ar shielding $\mu \mathrm{PAW}, 5 \mathrm{~A}, 0.06 \mathrm{~s}$, , Kroll etchant, $550 \mathrm{HV}$, pink NiTi [12, precipitation of $\mathrm{Ti}_{2} \mathrm{Ni}, \mathrm{Ni}_{3} \mathrm{Ti}$.

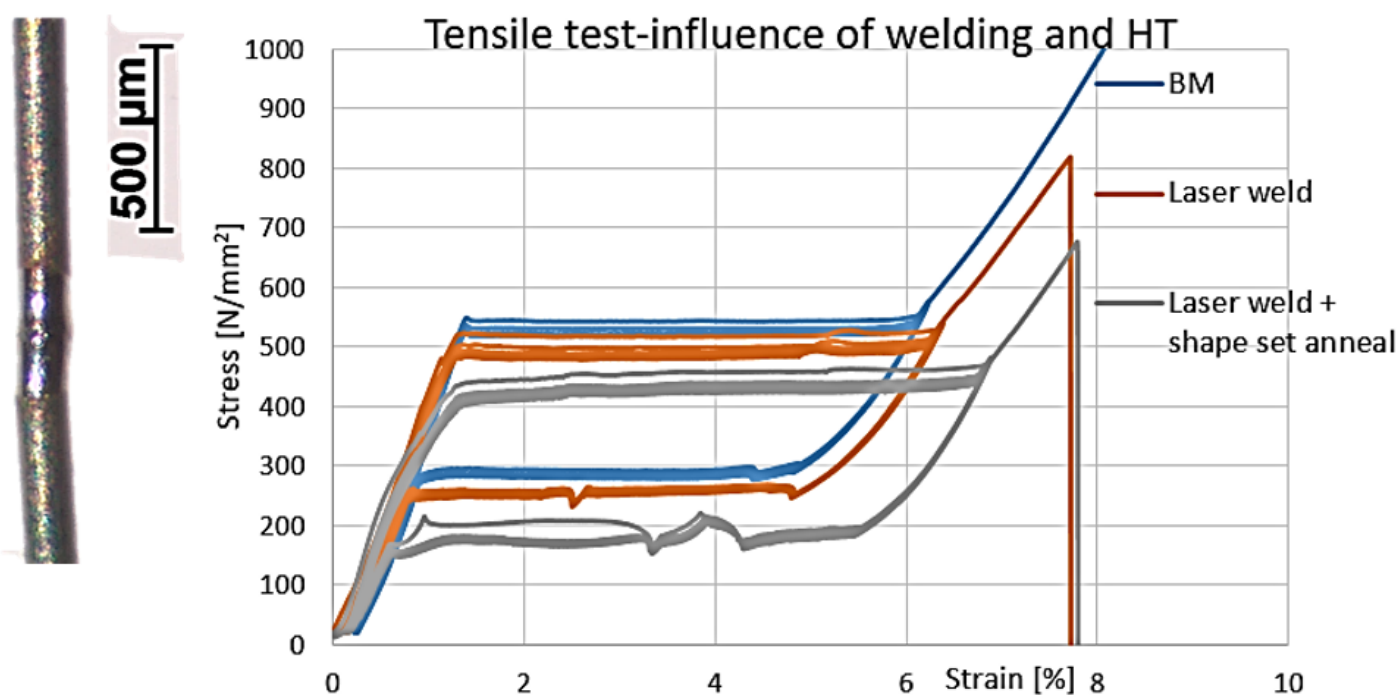

Figure 12. Tensile test, $\varnothing 0.15 \mathrm{~mm}$ (4 cycles + until rupture): (1) base material, (2) welded, (3) welded and shape annealed. 


\subsection{LASER WELDing (LBW)}

The technology is usable for all wire diameters: the results for a $0.15 \mathrm{~mm}$ wire are shown. The welding parameters suitable for this wire diameter were: 1 pulse, $0.25 \mathrm{~kW}, 4 \mathrm{~ms}(1 \mathrm{~J})$.

The example of a weld with the best shape and shielding (no oxidation colours) is in Figure 12 together with the results of the tensile test. The results of the tensile test of the original wire sample, welded and heat treated (shape set annealed), are shown. For this set of specimens only, the shape-set anneal after welding was done and shown.

The original $0.15 \mathrm{~mm}$ wire had a UTS of around $1600 \mathrm{~N} / \mathrm{mm}^{2}$, an elongation at a break of $13 \%$. The welding and/or heat treatment causes a drop in all mechanical properties, UTS, UPS, LPS (lower plateau stress) and ductility. Even though the mechanical properties of the welded joint are decreased, the welded samples exhibit a pseudoelastic behaviour. The decrease of mechanical properties (UTS, UPS, LPS) is further aggravated by further heat treatment, in our case, a shape-set annealing $\left(500{ }^{\circ} \mathrm{C}, 20 \mathrm{~min}\right)$. The distance of UPS-LPS (pseudoelastic hysteresis) is, for all cases, $250 \mathrm{~N} / \mathrm{mm}^{2}$. The comparison of the tensile test curves (Figure 12) shows that the welding and heat treatment causes irregularities (oscillations on the curve) during the phase transformation. The influence of the heat treatment on the tensile test curve shape was noted in the work of Heller 13 .

For some laser welds, it was found out that even under the conditions of optimum shielding, a slight oxidation of WM occurred, and in the case of a shielding disturbance, the weld behaved in a brittle manner. Similarly, as noted already for the PAW, the oxygen contamination is serious and causes a precipitation of the brittle intermetallic phases.

\subsection{Electron Beam Welding (EBW)}

The electron beam in a vacuum was used with the expectation of improved cleanliness and repetitiveness of the results, due to a small beam diameter, together with a limited variation of absorptivity. The disadvantage lies in the difficult manipulation and preparation. The welding parameters were $0.1 \mathrm{~mA}$, the voltage of the source was fixed to $60 \mathrm{kV}$, the length of pulses was $10-90 \mathrm{~ms}$. The weld and tensile test results are in Figures 1315 The loading/unloading transformation stress is similar to the base material. The fracture of the welded specimen was at $900 \mathrm{~N} / \mathrm{mm}^{2}$, the fracture was ductile and occurred in the HAZ. The original wire tensile strength is $1100 \mathrm{~N} / \mathrm{mm}^{2}$. The fact that the specimen could repetitively undergo the phase transformation and that the fracture had a ductile behaviour was the proof of the good quality of the welding process. The basic advantage of the EBW is the presence of a vacuum leading to a complete absence of oxygen, that the uniform welds can be repeated and that the mechanical properties are good. The welded samples had a UTS range of $600-900 \mathrm{~N} / \mathrm{mm}^{2}$. All

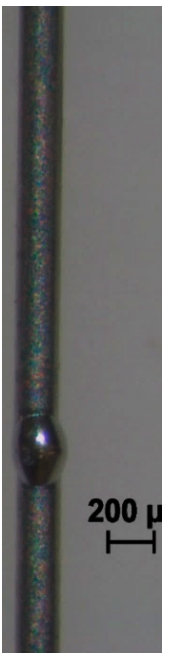

Figure 13. EBW weld, on $0.15 \mathrm{~mm}-60 \mathrm{kV}, 0.1 \mathrm{~mA}$, pulse $10 \mathrm{~ms}$, energy $0.1 \mathrm{~J}$.

the tested specimens were undergoing pseudoelastic transformation when tested in tension and fractured at the welded joint.

All fusion welding techniques, under optimum parameters, resulted in welds retaining their pseudoelastic properties. Under the prerequisites to minimize heat input and prevent oxidation, the results reached with the EBW, LBW were much better than those in PAW.

\subsection{Pressure Welding}

After the fusion welding tests, the experiment continued with the pressure welding techniques. A deformation during the welding, small grains and good properties were expected in connection with the pressure.

\subsection{Resistance Butt Welding (RBW)}

The welding parameters for a $\varnothing 0.46 \mathrm{~mm}$ wire were $0.85 \mathrm{~V}, 350 \mathrm{~A}$. Due to the process characteristics, the exact heat input cannot be calculated, as the welding time is not directly measured as it is determined by the jaw distance, the spring setting and the joint formation. The welding time was, approximately, $0.1 \mathrm{~s}$; thus, the energies were around $3 \mathrm{~J}$. The weld is shown in Figure 16. The resistance butt welding flash was removed by mechanical shearing and/or grinding that is not shown here.

In the tensile test, the RBW specimens overall showed a pseudoelastic behaviour; the UTS of the tested joints was in the range of $540-750 \mathrm{~N} / \mathrm{mm}^{2}$.

The microstructure of the BM, Figure 18 , shows prolonged and fragmented inclusions in the drawing direction. The grains are of dimensions under $10 \mu \mathrm{m}$. The size of a grain in the WM, Figure 19 increases to the range of $10-20 \mu \mathrm{m}$ and the number of particles and inclusions increases substantially. As can be seen in the hardness indentations on Figure 17, the hardness (HV0.2) remains almost constant across the joint. The 


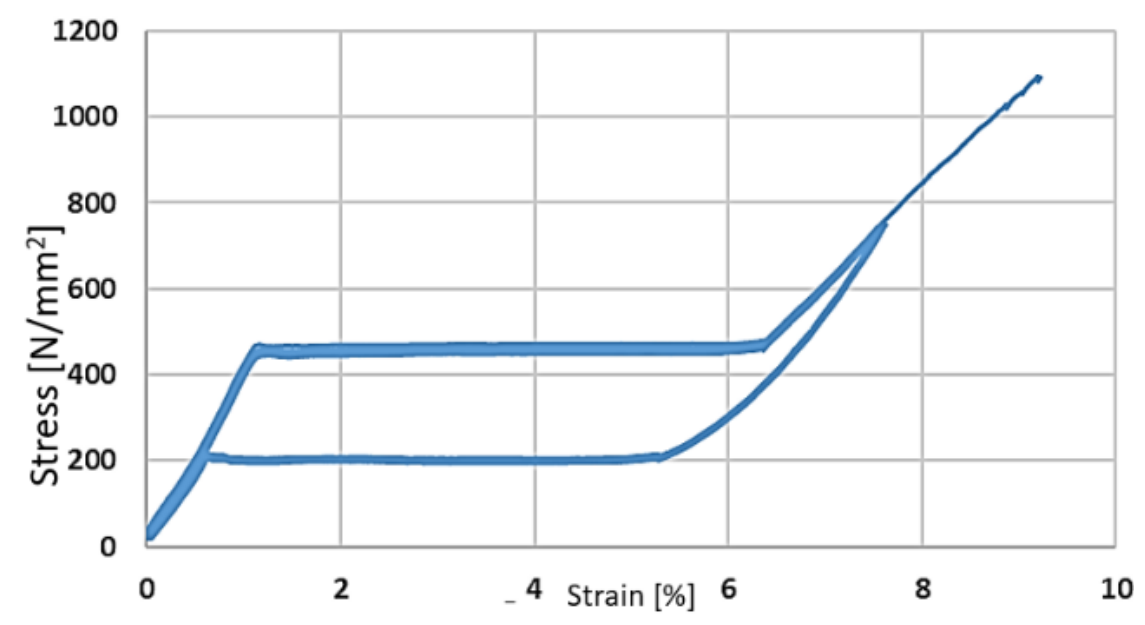

FiguRE 14. Stress-strain diagram of base material, tensile test, 4 cycles+till rupture.

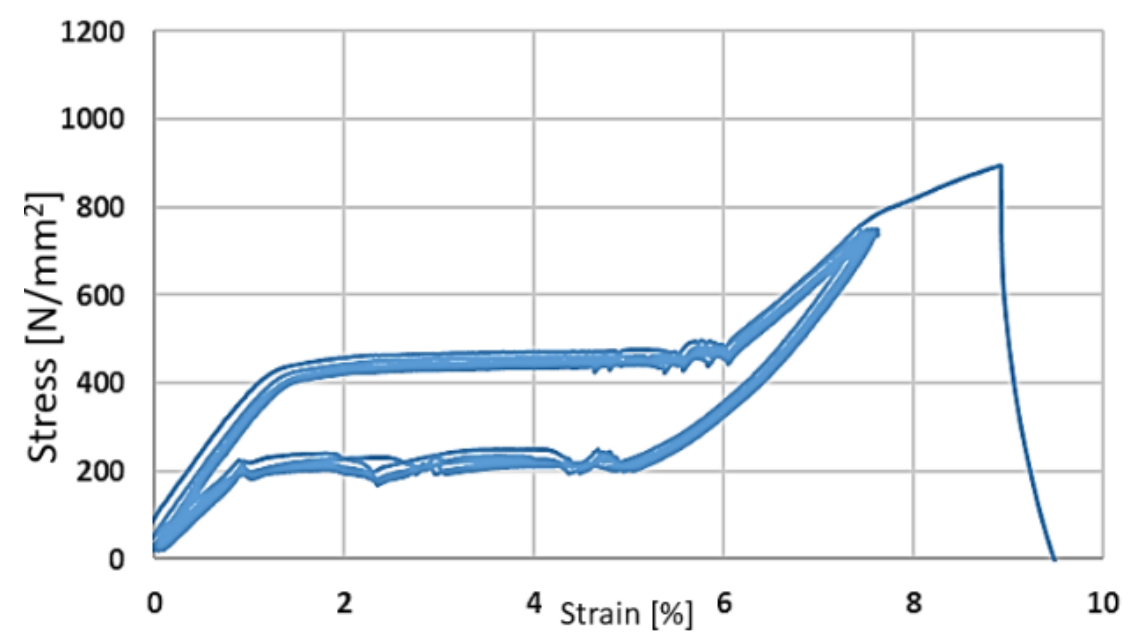

Figure 15. Stress-strain diagram of EWB sample, tensile test, 4 cycles+till rupture similar to BM, best result.

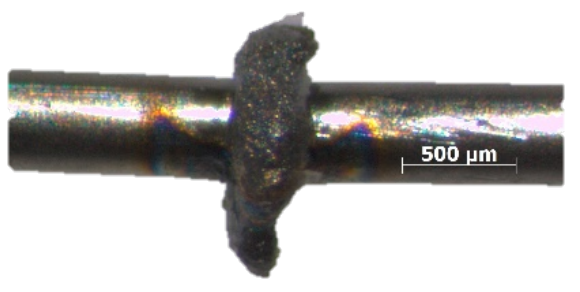

Figure 16. RBW sample $0.46 \mathrm{~mm}$, etched wire.

grain size in the WM is $10-20 \mu \mathrm{m}$, the grains are the smallest from all the tested weld techniques and they do not have such cast character due to deformation upon cooling.

\subsection{Capacitor Discharge Welding (CDW)}

On the one hand, from all the processes, the capacitor discharge welding enables the shortest welding time, around $40 \mu \mathrm{s}$, which could present an advantage. The laser had $4 \mathrm{~ms}$, the electron beam $90 \mathrm{~ms}$, and the resistance welding $100 \mathrm{~ms}$. On the other hand, the capacitor discharge is difficult to control precisely, thus the energy input varies in many factors; e.g.,

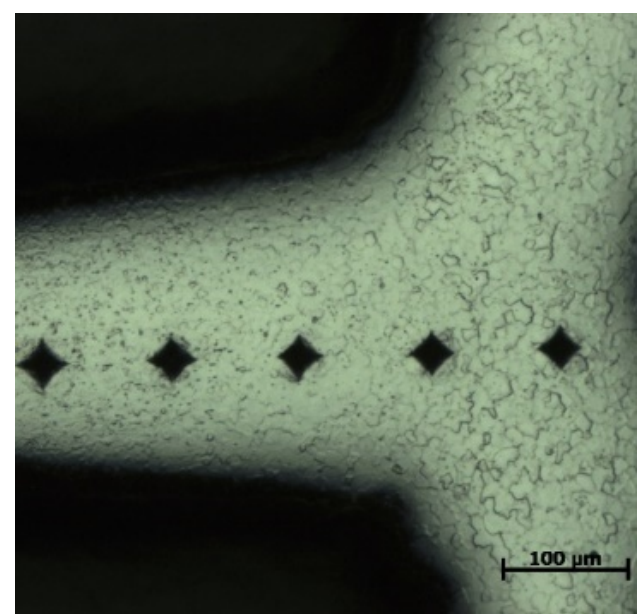

FiguRE 17. Half section of RBW $0.46 \mathrm{~mm}$, etched Kroll.

the state of the capacitor, the delay between pulses, the wire cutting, the pressure; thus, the energy varies between 40-80 mJ. The repeatability in the manual process was not easy. The WM shows a cast structure, with grains of 20-300 $\mu \mathrm{m}$. 


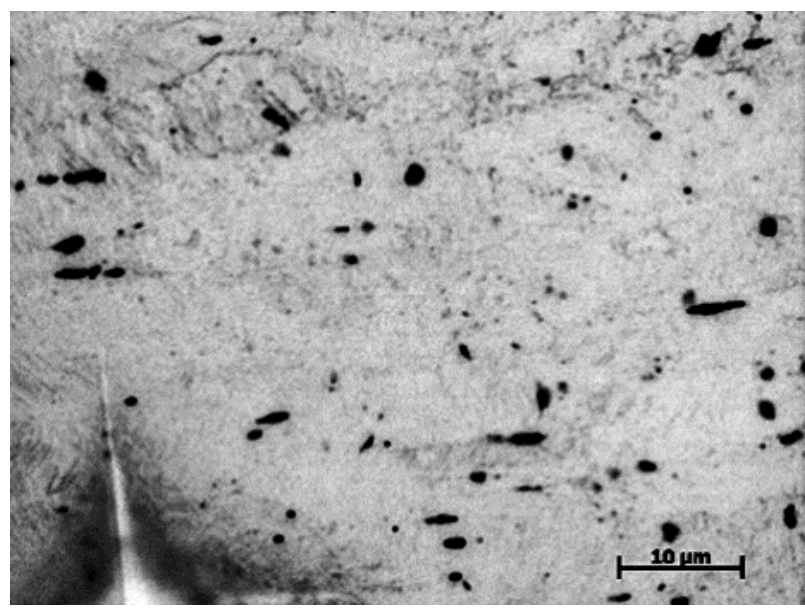

Figure 18. BM, RBW 0.46 mm, etched Kroll.

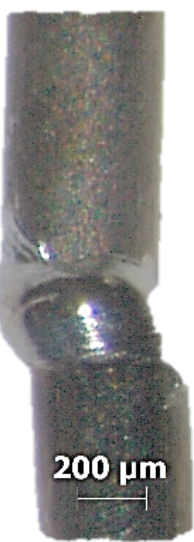

FiguRE 20. CDW sample $0.46 \mathrm{~mm}$, discharge energy 40-80 mJ, 1 pulse, left after welding, right fractured at $240 \mathrm{MPa}$.

The welds underwent a tensile testing with the results ranging between $160-630 \mathrm{~N} / \mathrm{mm}^{2}$, all the welds being fractured in the WM or at the fusion boundary, Figure 20. The wide range of the UTS is caused by the CDW process characteristic and the manual manipulation during welding. The best results enabled a pseudoelastic behaviour of the sample.

\section{Conclusions}

In Table 1, the summary of all the welding methods and the results of tests is visible. The majority of specimens welded under good shielding by the LBW, EBW did fracture above the transformation stress. None of the specimens (with the exception of 1 sample, done by the RBW) did prove pseudoelastic behaviour in a localized bending in the WM zone. Obviously, the re-melting, the grain coarsening renders the weld metal lose its pseudoelastic properties. The HAZ remains pseudoelastic. Clearly, the smaller the weld, the better.

The experiments show similar tendencies, and the conditions of the NiTi wire welding can be summarized as follows:

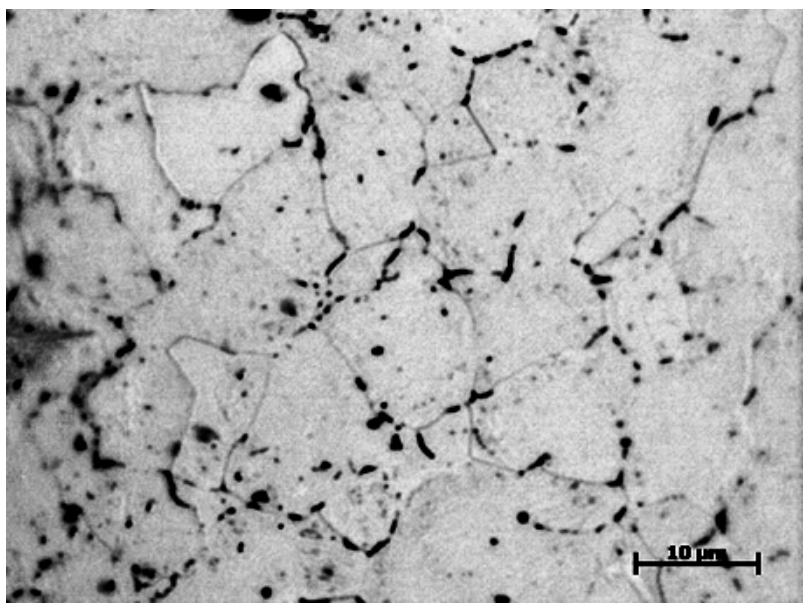

Figure 19. WM, RBW 0.46 mm, etched Kroll.

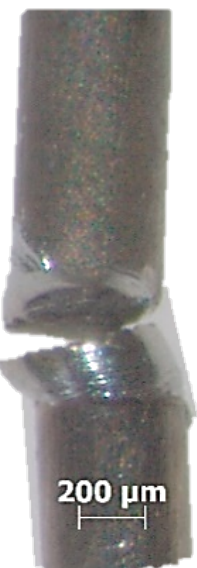

(1.) A welding source suitable for a precise heat input control is a must. The needed energies for the thin wire welding are extremely small $(0.1-1 \mathrm{~J})$. Heat has a clearly negative effect on $\mathrm{NiTi}$; because of heat, the re-melting enables the creation of intermetallic phases $\mathrm{Ti}_{2} \mathrm{Ni}, \mathrm{TiNi}_{3}$ that are more stable than NiTi. To minimize heat input is a must.

(2.) All sources of contamination must be eliminated. A source of impurities, of detrimental elements can be:

(a) BM - contains typically a small amount of impurities, inclusions, which are limited and controlled by the norm

(b) BM surface - surface can be a source of oxides, hydrocarbons, water - the base material surface oxides should be grinded, etched away before starting welding, or one should buy etched or/and mechanically cleaned wires

(c) The welding process - Inert gas shielding is very important: a contamination by oxygen or hydrogen causes the creation of intermetallic phases. The weld must be shielded perfectly; welding in a vacuum is recommendable. The best solution is the EBW in a vacuum. 


\begin{tabular}{|c|c|c|c|c|c|c|c|}
\hline \multicolumn{2}{|c|}{$\begin{array}{l}\text { Welding } \\
\text { method }\end{array}$} & $\begin{array}{c}\text { Suitable } \\
\text { for wire } \varnothing\end{array}$ & $\begin{array}{c}\text { UTS } \\
{\left[\mathrm{N} / \mathrm{mm}^{2}\right]}\end{array}$ & $\begin{array}{c}\text { Fractured } \\
\text { at }\end{array}$ & $\begin{array}{c}\text { Pseudoelastic } \\
\text { behaviour } \\
\text { in tensile test }\end{array}$ & $\begin{array}{c}\text { Bending test - } \\
\text { straightness } \\
\text { recovery in WM }\end{array}$ & $\begin{array}{l}\text { Structure } \\
\text { of WM }\end{array}$ \\
\hline & $\mathrm{BM}$ & & $1100-1600$ & & Yes & Yes & $\begin{array}{c}\text { Cold work } \\
\text { and straight } \\
\text { annealed }\end{array}$ \\
\hline $\begin{array}{l}\text { Fusion } \\
\text { welding }\end{array}$ & $\begin{array}{l}\mu \mathrm{PAW} \\
\mathrm{LBW} \\
\mathrm{EBW}\end{array}$ & $\begin{array}{l}>0.38 \mathrm{~mm} \\
>0.15 \mathrm{~mm} \\
>0.15 \mathrm{~mm}\end{array}$ & $\begin{array}{l}370-480 \\
800-900 \\
600-900\end{array}$ & $\begin{array}{l}\text { WM, HAZ } \\
\text { WM, HAZ } \\
\text { WM, HAZ }\end{array}$ & $\begin{array}{l}\text { Some samples } \\
\text { Majority } \\
\text { All samples }\end{array}$ & $\begin{array}{l}\text { No } \\
\text { No } \\
\text { No }\end{array}$ & $\begin{array}{l}\text { As cast } \\
\text { As cast } \\
\text { As cast }\end{array}$ \\
\hline $\begin{array}{l}\text { Pressure } \\
\text { welding }\end{array}$ & $\begin{array}{l}\text { RBW } \\
\text { CDW }\end{array}$ & $\begin{array}{l}>0.18 \mathrm{~mm} \\
>0.38 \mathrm{~mm}\end{array}$ & $540-750$ & WM, HAZ & $\begin{array}{l}\text { Some samples } \\
\text { Some samples }\end{array}$ & $\begin{array}{l}\text { One sample yes, } \\
\text { rest no } \\
\text { No }\end{array}$ & $\begin{array}{l}\text { Recrystallized } \\
\text { grains } \\
\text { As cast }\end{array}$ \\
\hline
\end{tabular}

TABLE 1. Overall comparison table of welding methods and results.

Under the best welding conditions, the fusion welds will have mechanical properties close to the original wire. The pseudoelastic plateau will be the same as that of the original wire, the UTS close to the BM (a decrease to $80 \%$ of the original strength due to a recrystallization of the drawn wire).

The pressure welds results widely varied. The CDW results were not satisfactory due to a result variability, a loss of pseudoelasticity, etc. This is probably caused by an inability to set the source precisely. However, the RBW welds exhibited pseudoelastic behaviour in tension for the majority of samples.

Overall, the best results have been obtained using the LBW due to its short pulse; using the EBW due to its operation in vacuum; using the RBW due to its principle of the axial pressure, movement. It is expected that these results can be further improved by a proper tooling and a post-weld heat treatment, which is the next step of this research.

\section{ACKNOWLEDGEMENTS}

Authors acknowledge the support from the ESIF, EU Operational Programme Research, Development and Education, and from the Center of Advanced Aerospace Technology (CZ.02.1.01/0.0/0.0/16_019/0000826), Faculty of Mechanical Engineering, Czech Technical University in Prague. The research was supported by SGS16/217/OHK2/3T/12. The authors also give sincere thanks to the team of the Department of Functional Materials, Institute of Physics CAS and Department of Microelectronics, FEL, CTU in Prague.

\section{REFERENCES}

[1] Company materials ELLA-CS, s.r.o., 2018

[2] Otsuka K, Ren X. Physical metallurgy of Ti-Ni-based shape memory alloys. Prog Mater Sci 2005;50:511-678. DOI:10.1016/j.pmatsci.2004.10.001

[3] Oliveira J, Miranda R, Braz F. Welding and Joining of NiTi Shape Memory, Alloys: A Review, Prog Mater Sci 2017. DOI:10.1016/j.pmatsci.2017.04.008

[4] Elahinia M, Hashemi M, Tabesh M. Manufacturing and processing of NiTi implants: A review. Progress in Materials Science 2012. DOI:10.1016/j.pmatsci.2011.11.001

[5] Novak P et al. Formation of Ni-Ti intermetallics during reactive sintering at $800-900^{\circ} \mathrm{C}$, Materials and technology 51 (2017) 4, 679-685, DOI:10.17222/mit.2016.257

[6] Skolakova A, Novak P, Salvetr P. Influence of elements with high affinity to oxygen on microstructure and phase composition of Ni-Ti alloy. Manufacturing Technology, 2017, 808-814

[7] Company materials EWM AG, 2018

[8] Company materials OR Laser Technology Inc., 2018

[9] Company materials, August Strecker GmBH., 2018

[10] Company materials, Svarservis s.r.o., 2018

[11] Tauer J. Joining of nitinol with stainless steel in medical catheters, bachelor thesis, CTU in Prague, 2018

[12] Vondrous P, Kolarik L, Kolarikova M. Plasma arc welding of NiTi and 304 steel, Annals of DAAAM 2012

[13] Heller L et al., On the plastic deformation accompanying cyclic martensitic transformation in thermomechanically loaded NiTi, International Journal of Plasticity (2018), DOI:10.1016/j.ijplas.2018.07.007 